\title{
Diagenetic and metamorphic overprint and deformation history of Permo-Triassic Tethyan sediments, SE Tibet
}

\author{
István Dunkl ${ }^{1}$, Ding Lin², Chiara Montomoli ${ }^{3}$ Klaus Wemmer ${ }^{1}$, Gerd Rantitsch ${ }^{4}$, Borja Antolin ${ }^{5}$, \\ Rachida El Bay ${ }^{5}$ and Erwin Appel ${ }^{*}$
}

1 University of Göttingen, GERMANY

2 Instititute of Tibetan Plateau Research, CAS, Beijing, CHINA

3 University of Pisa, ITALY

4 University of Leoben, AUSTRIA

5 University of Tübingen, GERMANY

* For correspondence, email: erwin.appel@uni-tuebingen.de

We have studied the deformation history and the grade and age of metamorphic overprint of the folded and imbricated Permo-Triassic limestone and flysch sequences of the Tethyan Himalaya in several strike-perpendicular profiles in SE Tibet in order to supply time and temperature constraints for a running paleomagnetic study and to describe the behaviour of the hanging wall of STDS.

The longest profile (ca. $40 \mathrm{~km}$ ) runs from Tsetang to the SW and exposes mainly Triassic flysch. The deformation at the southern part is weak, big-scale, south-vergent isoclinal folds are characteristic foliation associated to folds is mainly a stilolitic surface with dominant pressure solution. At the northern part of the profile a second, top-to-north folding event generated a complex deformation pattern and locally intense neo-crystallization of illite-sericite, gives rise to a fine continuous foliation parallel to axial planes of folds. The applied methods were "illite crystallinity" (results are expressed as Kübler Index: KI), vitrinite reflectance (VR), K/Ar geochronology and microtectonic analyses. The appearance of the Tethyan sedimentary formations suggests a very wide range of overprint: in some sites fossiles and sedimentary micromorphological elements are well preserved, while in other tectonic blocks the formations experienced metamorphism in greenschist facies. The analytical results reflect well the variable overprint: VR ranges from $1.8 \%$ to the graphite stage, and KI ranges from 0.38 to $0.17^{\circ}$. The majority of $\mathrm{K} / \mathrm{Ar}$ results is interpreted as mixed age, because the shift of apparent ages between $106 \mathrm{Ma}$ and $24 \mathrm{Ma}$ shows good correlation with decreasing KI. The most recrystallized samples (KI ca. $0.17^{\circ}$ ) show no reaction after ethylenglycol treatment and they have uniform $\mathrm{K} / \mathrm{Ar}$ ages in the $<2 \mu \mathrm{m}$ and $<0.2 \mu \mathrm{m}$ grain size fractions around ca. $24 \mathrm{Ma}$. We suppose that these ages are close to the climax of the second, top-to-north folding event. Probably the structural block in the middle of the Tsetang profile showing the highest degree of metamorphism is structurally related to the Yalar Xiangbo dome.

Late orogenic large-scale deformations have been recorded in many areas of the Tethyan Himalaya by stable secondary magnetizations residing in pyrrhotite and postdating main Himalayan folding. In SE Tibet, however, a complex magnetic behaviour (noisy demagnetization, scattering remanence directions, very variable pyrrhotite content) is observed and paleomagnetic data have to be analyzed and interpreted with thorough selection criteria based on the thermal history and deformation style. 